ELECTRICAL PRINCIPLES II 
Macmillan Technician Series

P. Astley, Engineering Drawing and Design II

P. J. Avard and J. Cross, Workshop Processes and Materials I

G. D. Bishop, Electronics II

John Elliott, Building Science and Materials

D. E. Hewitt, Engineering Science II

P. R. Lancaster and D. Mitchell, Mechanical Science III

R. Lewis, Physical Science I

Noel M. Morris, Electrical Principles III 


\title{
ELECTRICAL PRINCIPLES II
}

\author{
Noel M. Morris \\ Principal Lecturer, \\ North Staffordshire Polytechnic
}


All rights reserved. No part of this publication may be reproduced or transmitted, in any form or by any means, without permission.

First published 1977 by

THE MACMILLAN PRESS LIMITED

London and Basingstoke

Associated companies in Delhi Dublin

Hong Kong Johannesburg Lagos Melbourne

New York Singapore and Tokyo

Typeset in 10/12 Times

\title{
British Library Cataloguing in Publication Data
}

\author{
Morris, Noel Malcolm \\ Electrical principles II.-(Macmillan \\ technician series). \\ 1. Electric engineering \\ I. Title II. Series \\ $621.3 \quad$ Tk145
}

\section{ISBN 978-0-333-22062-7 ISBN 978-1-349-03426-0 (eBook)}

DOI 10.1007/978-1-349-03426-0

This book is sold subject to the standard conditions of the Net Book Agreement.

The paperback edition of this book is sold subject to the condition that it shall not, by way of trade or otherwise, be lent, resold, hired out, or otherwise circulated without the publisher's prior consent in any form of binding or cover other than that in which it is published and without a similar condition including this condition being imposed on the subsequent purchaser. 


\section{Contents}

Preface

vii

1. Electrical Units

1.1 Basic Units

1.2 Multiples and Submultiples

1.3 Derived Mechanical Units

1.4 Electrical Units in Direct-current Circuits Problems

2. D.C. Circuits

2.1 Resistors in Series and in Parallel

2.2 Series - Parallel Resistor Circuits

2.3 Conductance

2.4 A Notation for Voltages and Currents

2.5 Kirchhoff's Laws

2.6 The Superposition Theorem Problems

\section{Capacitors and Capacitance}

3.1 The Constitution of Matter

3.2 Force between Charged Bodies

3.3 Electric Fields and Electric-field Strength

3.4 Electrostatic Screening

3.5 The Relationship between Charge, Capacitance and Voltage

3.6 Capacitor Current due to Change of Voltage

3.7 Electric Flux and Flux Density

3.8 Permittivity

3.9 Capacitance of Parallel-plate Capacitors

3.10 Parallel-connected Capacitors

3.11 Series-connected Capacitors

3.12 Series - Parallel Capacitor Combinations

3.13 Energy Stored in a Capacitor

3.14 Types of Capacitor Problems
4. The Magnetic Field

4.1 Magnetic Field, Magnetic Flux and Flux Density

4.2 Magnetomotive Force and Magnetic-field Strength

4.3 Permeability

4.4. Magnetisation Curves of Ferromagnetic Materials

4.5 Hysteresis Loop

4.6 Hysteresis Loss 32

4.7 Reluctance 33

4.8 Magnetic Circuits 33

4.9 Magnetic Screening 37 Problems $\quad 37$

5. Electromagnetic Induction 39

5.1 The Basis of Electromagnetic Induction 39

5.2 The Laws of Electromagnetic Induction 39

5.3 Interpretation of Lenz's Law 41

5.4 Induced E.M.F. due to Motion 42

5.5 Fleming's Right-hand Rule 43

5.6 Principle of Electric Motor Action 43

5.7 Fleming's Left-hand Rule

5.8 Force on a Current-carrying Conductor in a Magnetic Field

5.9 Torque Developed by a Rudimentary Electrical Machine

5.10 Self-inductance

5.11 Relationship between Self-inductance and Number of Turns

5.12 Energy Stored in a Magnetic Field

5.13 Mutual Inductance

5.14 Transformer Principles Problems

6. Alternating Voltage and Current

6.1 Alternating Quantities

6.2 Sinusoidal Waveforms 
6.3 Non-sinusoidal Waveforms 53

6.4 The Simple Alternator

6.5 Frequency

6.6 Periodic Time

6.7 Mean Value or Average Value of an Alternating Waveform

6.8 Root-mean-square (r.m.s.) Value of an Alternating Waveform

6.9 Form Factor and Peak Factor

6.10 Graphical Representation of Alternating Quantities

6.11 Phase-angle Difference

6.12 Phasor Diagrams

6.13 Addition of Phasors

6.14 Subtraction of Phasors Problems

7. Single-phase A.C. Circuits

7.1 Circuit containing a Pure Resistance

7.2 Circuit containing a Pure Inductance

7.3 Inductive Reactance

7.4 Effect of Frequency on Inductive Reactance

7.5 Circuit containing a Pure Capacitance

7.6 Capacitive Reactance

7.7 Effect of Frequency on Capacitive Reactance

7.8 Series Circuit containing Resistance and Inductance

7.9 Series Circuit containing Resistance and Capacitance

7.10 Series Circuit containing Resistance, Inductance and Capacitance

7.11 Series Resonance

$7.12 Q$-factor of the Series Resonant Circuit

7.13 Power, Volt-amperes and Reactive Volt-amperes Problems

8. Measuring Instruments and Measurements

8.1 Types of Instrument
8.2 Effects Utilised in Analogue Instruments

8.3 Requirements of Analogue Instruments

8.4 Controlling Systems

8.5 Damping Systems

8.6 Methods of Supporting Moving Systems

8.7 Instrument Scales

8.8 Moving-coil Instruments or Galvanometers 80

8.9 Moving-iron Instruments 81

8.10 Electrodynamic or Dynamometer Instruments 82

8.11 Extension of Instrument Range 82

8.12 Ohmmeters 85

8.13 Instrument Sensitivity and Accuracy 85

8.14 Measurements with Electronic Instruments $\quad 86$

8.15 The D.C. Potentiometer 86

8.16 The Wheatstone Bridge $\quad 87$

8.17 The Cathode-ray Oscilloscope $\quad 88$

Problems $\quad 89$

9. Rectifiers 91

9.1 Semiconductors 91

9.2 Diodes 92

9.3 Zener Diodes 92

9.4 Thermionic Diodes 93

9.5 Rectifier Circuits 93

Problems 95

10. Transistors, Triodes and Amplifiers 96

10.1 Bipolar Junction Transistors 96

10.2 Field-effect Transistors 98

10.3 Triodes 99

10.4 Amplifier Classification $\quad 100$

10.5 A Fixed-bias Common-emitter Small-signal Amplifier

10.6 Load-line Construction for Resistive Loads 102

10.7 Common-emitter Transfer Characteristics 104

10.8 Small-signal Common-cathode Triode Amplifier Problems

Solutions to Numerical Problems 


\section{Preface}

A sound knowledge of the principles of electricity is essential to technicians in all branches of the electrical and electronics industry; this book covers the requirements of Principles of Electricity II of TEC courses.

The book is divided into ten chapters to provide a step-by-step development of the main areas of work. Examples, both worked and unworked, are included. The first chapter deals with the fundamental units of electricity together with associated mechanical quantities. There follows a chapter on d.c. circuits in which methods of dealing with a range of circuits and described. In chapter 3, capacitors and capacitor combinations are discussed. In chapters 4 and 5 the important topics of magnetic fields and electromagnetic induction are dealt with, leading to the basic principle of the transformer. Chapter 6 covers the basis of alternating-current theory, which leads to work on single-phase a.c. circuits in chapter 7 . Chapter 8 is devoted to the important topic of measuring instruments and measurements. The final two chapters deal with aspects of electronics, including diodes, rectifier circuits, transistors and amplifiers.

I would like to thank the editorial and production staff of the Macmillan Press for their advice and help during the production of the book. Finally, it is a pleasure to thank my wife for her excellent work during its preparation.

NOEL M. MORRIS 